\title{
DESIGN METHOD FOR CORNER CONNECTION BETWEEN SANDWICH AND OPEN-SANDWICH COMPOSITE MEMBERS SUBJECTED TO BENDING MOMENT
}

\author{
By Virach RUNGROJSARATIS* and Tamon UEDA**
}

\begin{abstract}
With the aim to fill up the gap in design method for connection between different types of structural member, corner connection between sandwich and open-sandwich composite members was studied. Experiments of corner connection were conducted by varying details of reinforcing bars, steel web and steel flange in the joint. Based on the test results, the design method for corner connection between sandwich and open-sandwich composite members subjected to bending moment was proposed. The proposed method includes the basic designs of force transfer among concrete, deformed bars and steel plate which can be applied for design of connection between different types of structural member.

Keywords : sandwich, open-sandwich, joint, mixed structural system, tail extension length
\end{abstract}

\section{INTRODUCTION}

To serve as structures of which required performances are much complicated, the system so called mixed structural system was originated. The mixed structural system can utilize the merit of different structural types, such as steel structure, reinforced concrete structure etc., which are the components of the system. The combination of different structural types, however, arises the problem on design method for connection between different structural types which is not available so far. With the aim to fill up the gap in design method for connections between different types of structural members, corner connection between sandwich and open-sandwich composite members was selected as a case study. Sandwich composite member here is defined as a member employing structural steel plate as the facings and concrete as core while an open-sandwich composite member is defined as a member in which one of steel facings is replaced by reinforcing bars as shown in Fig. 1. The possible applications of these composite members can be found in offshore structures, for instance a submerged tunnel structure. As shown in Fig. 2, the structure is composed of two sandwich walls and two open-sandwich slabs connected at the corner. Two types of corner connection between sandwich and open-sandwich composite members designated as T-type and B-type can be distinguished as shown in Fig. 3. The difference between them is just the location of reinforcing bars

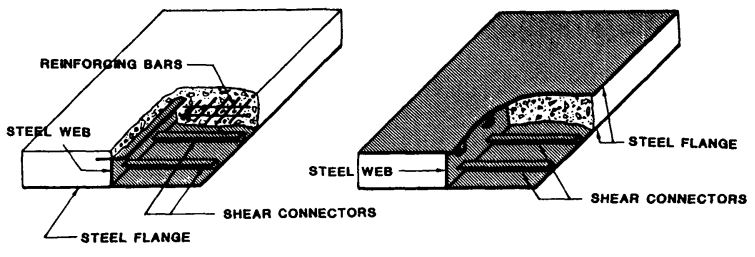

OPEN SANDWICH TYPE SANDWICH TYPE

Fig. 1 Sandwich type of composite member.

* Graduate student, Dept. of Civil Eng., Univ. of Tokyo (Bunkyo-ku, Tokyo 113).

** Member of JSCE, Assist. Prof., Div. of Struct. Eng. \& Const., A.I. T. (Bangkok, Thailand). 
which is at the outer corner for T-type and at the inner corner for B-type.

\section{PRELIMINARY STUDY OF CORNER CONNECTION BETWEEN SANDWICH AND OPEN-SANDWICH COMPOSITE MEMBERS}

Since there had been no study on the corner connection between sandwich and open-sandwich composite members, preliminary experiments were conducted to study ultimate strength of the corner connection subjected to both positive and negative moment (opening and closing). Detail arrangements of reinforcing bars, steel web and steel flange in the joint core were the investigated parameters. It should be noted that the terms of "steel flange" and "steel web" considered here are defined for the member as shown in Fig. 1, not for the whole structure level in Fig. 2.

(1) Detail of specimens and testing method

The test specimens were L-shaped specimens of which detail dimension and cross-section were given in Fig. 4. For all specimens, outer flange of sandwich wall was considered to extend through the joint region. Fig. 5 shows the difference in joint detailing of each specimen described below.

For T-type corner connection, three specimens were tested under negative moment (TC specimen) and

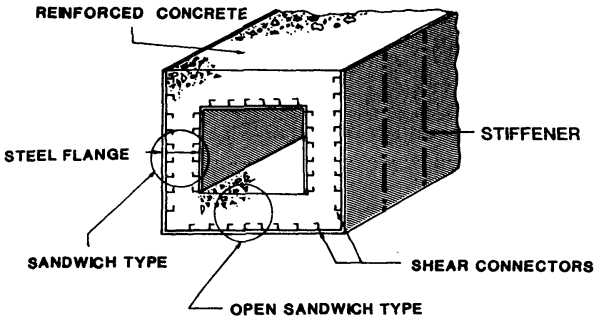

Fig. 2 Submerge tunnel structure.
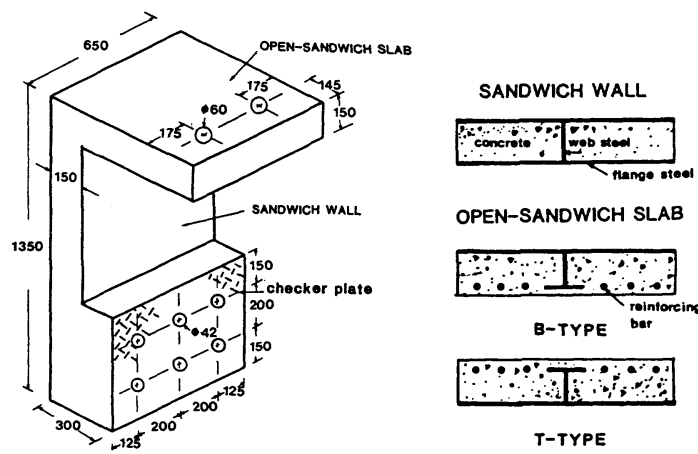

OPEN-SANDWICH SLAB

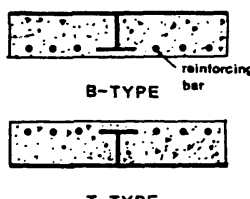

Fig. 4 Detail dimension and cross-section of specimen.

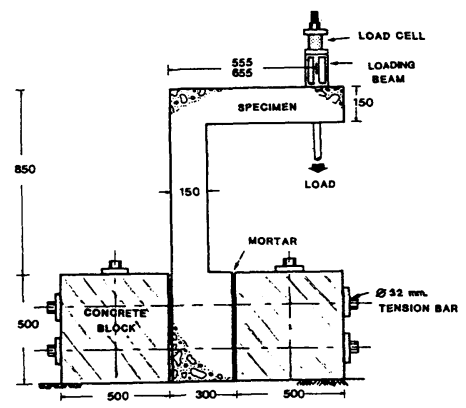

Fig. 6 Test arrangement.

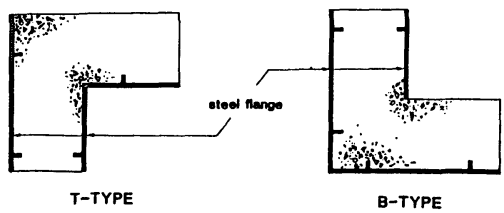

Fig. 3 Corner connection between sandwich and open-sandwich members.
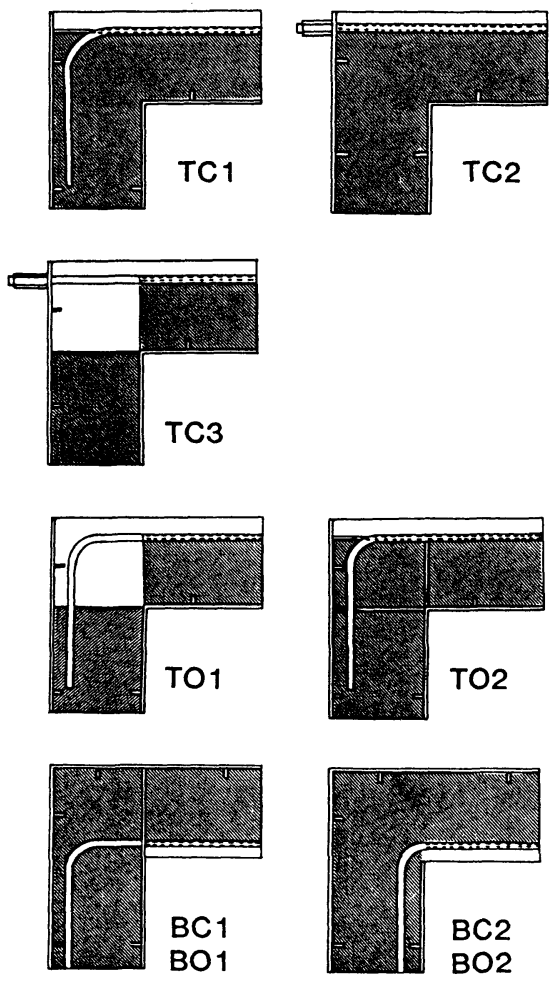

Fig. 5 Detail arrangement in joint core of test specimens. 
two specimens were subjected to positive moment (TO specimen). Detailing effect of reinforcing bar and web plate in joint core was studied in TC specimens. Standard hook bars ${ }^{1), 2)}$ were arranged in specimen TC 1 while, for specimens $\mathrm{TC}_{2}$ and $\mathrm{TC} 3$, reinforcing bars were directly connected to outer flange of sandwich wall by mechanical bolts. There is web plate in joint core for specimens TC 1 and TC 2 but not for specimen TC 3. The same arrangement of reinforcing bar as TC 1 was found in TO specimen. No web plate exists in the corner core of specimen TO 1 however, there is web plate and prolonged inner flange for specimen TO 2.

Two specimens of B-type corner connection were tested under negative moment (BC specimen). Hook bar which is located close to outer flange of sandwich wall and extended inner flange were considered for specimen $\mathrm{BC} 1$. In detailing of specimen $\mathrm{BC} 2$, prolongation of inner flange was not considered and hook bar was placed at the inner flange side. There is web existing in joint core for both specimens. Another two specimens ( $\mathrm{BO} 1, \mathrm{BO} 2)$ being identical to specimens $\mathrm{BC} 1$ and $\mathrm{BC} 2$ respectively were also tested under positive moment as shown in Fig. 5.

The experiments were done by clamping specimen with two concrete blocks fixed at testing base as shown in Fig. 6. Load was applied to specimen at position of arbitrarily assumed inflection point through two prestressing bars which distributed to loading beam and specimen respectively.

( 2 ) Discussion on strength of corner connections

The results of ultimate strength of corner connection are shown in Table 1. It was found that most of the specimens were failed by premature failure before strength of adjoining members was attained except for B-type corner connection subjected to negative moment. The observed failure of test specimens is shown in Fig. 7.

a) T-type corner connection

Strength of specimen TC 1 was found to be governed by premature failure of rib on the outer flange of sandwich wall. Therefore, in order to improve performance of this corner connection, anchorage for outer flange of sandwich wall should be strengthened. It is noted, however, that increase of anchorage strength for outer flange in the joint region by strengthening rib itself or placing more number of ribs may be subjected to limitation because the length of the outer flange in the joint core is restricted. Anchorage failure of outer flange was prevented by direct connecting of reinforcing bars to outer flange using bolt in specimen TC 2 and TC 3, however, another premature failure of bearing in concrete was occurred. The results indicated that bend bars are preferable to increase bearing area below the bars. The placing of web is found to be able to increase strength of the joint as compared with specimens TC 2 and TC 3 . From the above discussion, the problem to be solved is how to connect outer flange as a tensile reinforcement with reinforcing bar coming to join in the joint. One possible approach is to implement anchorage of outer flange in the outside of joint region. This suggests that $\mathrm{T}$-type corner connection subjected to negative moment shall be designed as reinforced concrete corner connection in which there is tail extension of bars lapped to outer steel flange as illustrated in Fig. 8. The essential design aspects are detailing of reinforcing bars in the corner and required lapped length for lapped splice between steel bars and steel plate.

It was found that the adequate detailing of reinforcing bars for the corner connection subjected to negative moment could be attained by just providing sufficient bending radius of reinforcement in the corner. The required bend radius $\left(r_{c}\right)$ for main reinforcing bar to prevent bearing failure can be computed from Eq. (1) which is modified from Leonhardt Equation ${ }^{3)}$ by correcting the term representing for concrete strength given as follows

$$
\begin{aligned}
& r_{c}=\frac{0.08 d_{b} f_{y r}}{f_{t}} \sqrt{\frac{d_{b}}{e^{*}}} \ldots \ldots \ldots \ldots \ldots \ldots \ldots \ldots \ldots \ldots \ldots \ldots \ldots \ldots \ldots \ldots \ldots \ldots \\
& \text { where } \quad r_{c}=\text { bend radius }(\mathrm{mm}), \\
& f_{t}=\text { tensile strength of concrete }(\mathrm{MPa}), \\
&=0.269 f_{c}^{2 / 3}
\end{aligned}
$$



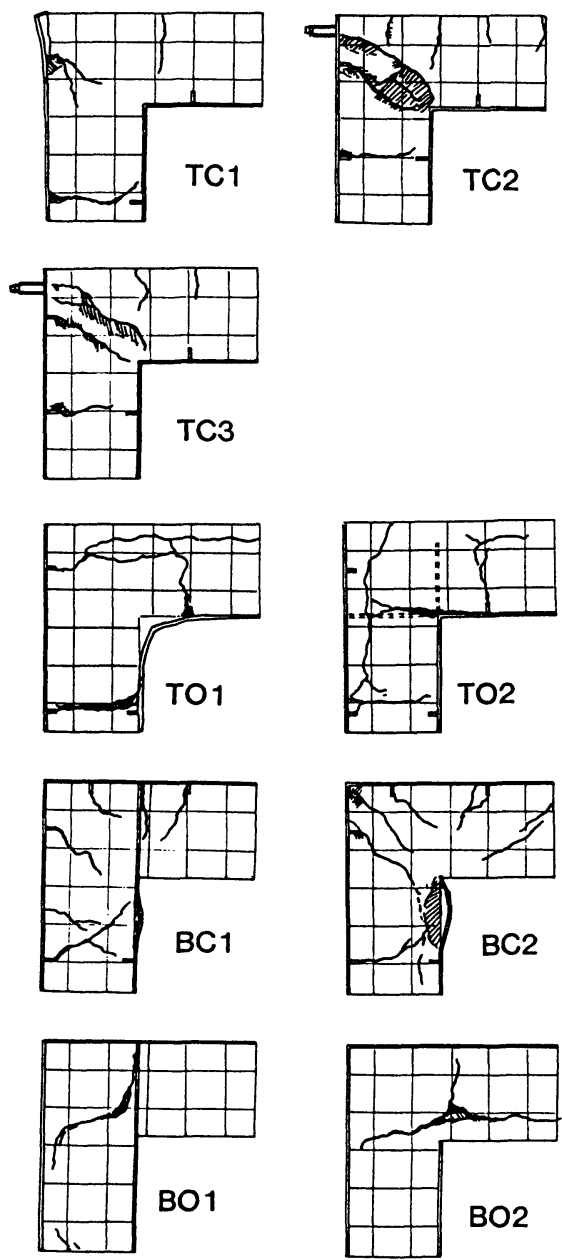

Fig. 7 Crack pattern and failure mode of corner joints.

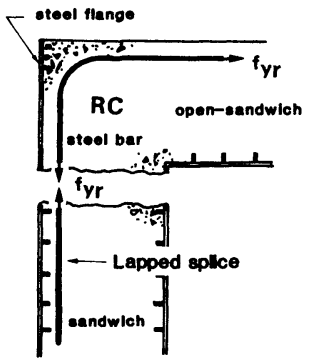

Fig. 8 Design approach for $\mathrm{T}$ type corner connection against negative moment.

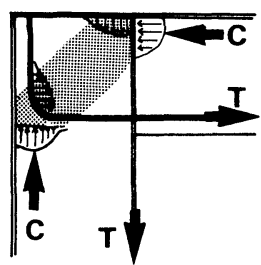

Fig. 10 Possible strut mechanism of B-type corner connection against positive moment.

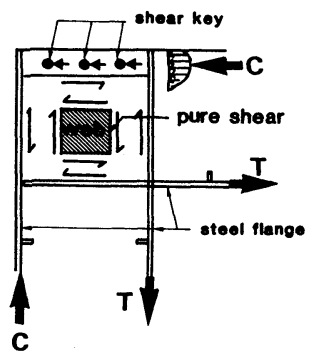

Fig. 9 Possible pure shear mechanism in T-type corner connection against positive moment.

$f_{c}=$ compressive concrete strength ( $\left.\mathrm{MPa}\right)$,

$f_{y r}=$ yield strength of reinforcing bar $(\mathrm{MPa})$,

$e^{*}=$ smaller of the following quantities $(\mathrm{mm})$

: distance between centers of two adjacent bars

: the covering increased by half of bar diameter,

$d_{b}=$ bar diameter $(\mathrm{mm})$.

It is noted that bend radius should not be larger than effective size of joint core which is $0.8 h$ where $h$ is minimum size of joint core $^{4)}$.

For a given lapped splice in which rib shear connectors are sufficient enough to prevent failure of rib itself, the required lapped length $\left(l_{s}\right)$ can be determined from the equation for the capacity of lapped splice between steel bar and steel plate ${ }^{5)}$, which is

$$
l_{s}=\frac{1}{8}\left(\frac{f_{y r}}{\left(0.45 B_{s} f_{t}+3.0\right)}\right)^{3 / 2} d_{b}
$$

where $B_{s}=$ normalized width of concrete

$$
=\left(b-n_{b} d_{b}\right) / n_{b} d_{b}
$$




$$
\begin{aligned}
b & =\text { width of sandwich wall, } \\
n_{b} & =\text { number of bars arranged within width } b .
\end{aligned}
$$

In the case of T-type corner connection subjected to positive moment, very low strength was obtained from the test results as shown in Table 1. Inner flange was not anchored well for specimen TO 1. Strength of specimen TO 2 was substantially improved by anchoring inner flange through web plate. However, due to insufficient thickness of web plate compared to large width of inner flange, the strength of corner connection governed by yielding of web plate was obtained before strength of adjoining members was attained. The strength contribution is believed to be obtained from pure shear mechanism in web panel like behavior of wide flange steel corner connection and composite action in the joint. Concrete can also confine web plate to prevent buckling of web. Therefore, it is suggested that corner connection can be strengthened by placing more web plates following conventional design approach of corner connection of wide flange steel members. According to the approach, axial forces and bending moment acting on the face of corner are assumed to be carried by steel flange causing a pure shear mechanism in web panel. Shear key, therefore, is also necessary to be provided in compression zone of open-sandwich slab for transferring compression force in concrete to web panel as shown in Fig.9.

The thickness of web $\left(t_{w}\right)$ required in the corner to provide against positive moment can be calculated from the following equation ${ }^{6)}$

$$
\begin{aligned}
t_{w}=\frac{\sqrt{3} f_{y f} t_{f} b}{h f_{y w}} & \ldots \ldots \ldots \ldots \ldots \ldots \ldots \ldots \ldots \ldots \ldots \ldots \ldots \ldots \ldots \ldots \ldots \ldots \ldots \ldots \ldots \ldots \ldots \ldots \ldots \ldots \ldots \ldots \\
\text { where } \quad t_{w} & =\text { required total web thickness }(\mathrm{mm}), \\
t_{f} & =\text { flange thickness }(\mathrm{mm}), \\
f_{y f} & =\text { yield strength of flange steel }(\mathrm{MPa}), \\
f_{y w} & =\text { yield strength of web steel }(\mathrm{MPa}), \\
h & =\text { minimum depth of adjoining members }(\mathrm{mm}) .
\end{aligned}
$$

Transverse reinforcing bars may be considered as shear key. Total yield forces acting at face of corner is considered to be transferred by bearing capacity or shear capacity of transverse reinforcing bar. According to Ikeda's study ${ }^{7}$, for a given bar diameter $\left(d_{b}\right)$ with minimum spacing of five times of bar diameter, the load transferring capacity is governed by shear failure of transverse reinforcement. Therefore, the number $\left(n_{s}\right)$ required for shear key in the joint core can be calculated from

$$
n_{s}=\frac{t_{f} b f_{y f}}{F_{s}}
$$

where $F_{s}=$ shear capacity per bar of transverse reinforcement

$$
=\pi d_{b}^{2} n_{w} f_{y r} / 2 \sqrt{3}
$$

$n_{w}=$ number of web plate arrange in the corner.

b) B-type corner connection

The test results shown in Table 1 indicate that the satisfactory performance of B-type corner connection was obtained for the specimens subjected to negative moment but not for the specimen subjected to positive moment. Flexure failure of sandwich wall was a dominant failure mode in specimens $\mathrm{BC} 1$ and $\mathrm{BC} 2$. The outer steel flange can confine joint core and create a strut mechanism in joint core without localized bearing failure as shown in Fig. 7. The detailing of reinforcing bar and inner flange was found not to be significant for strength of corner connection subjected to negative moment. For specimens $\mathrm{BO} 1$ and $\mathrm{BO} 2$, the similar failure mode was observed. The compression forces acting on both faces of the corner produce the large resultant of tension force in diagonal direction. This force induces failure of both specimens when a small resistance of concrete tension can not withstand anymore. It is suggested that the similar detail arrangement as reinforced concrete corner connection subjected to positive moment ${ }^{8)}$ should be considered. By bending up of hook bar and prolonging of inner flange as shown in Fig. 10, the diagonal strut can be formed in joint core. Reinforcing bars can be arranged by making holes in the extension of inner flange of 
sandwich wall. Hook bar can be designed by following the design of hook in reinforced concrete ${ }^{9)}$ given below.

$$
l_{d h}=\frac{f_{y r} d_{b}}{4.2 \sqrt{f_{c}}}
$$

where $l_{d h}$ is the length required between critical section and the outside end of hook bar. Critical section here is adopted to be the face of sandwich wall. In the case of corner connection subjected to moment reversal, some confinement ${ }^{9}$ should be provided for hook bar.

The design for thickness of extended inner flange to compensate the losing area due to hole can be simply regarded as follows

$$
\begin{aligned}
t_{f e}=\frac{b t_{f}}{\left(b-n_{h} \cdot d_{h}\right)} & \\
\text { where } \quad t_{f e} & =\text { thickness of extended inner flange }(\mathrm{mm}), \\
b & =\text { cross-sectional width of adjoining member }(\mathrm{mm}), \\
d_{h} & =\text { diameter of hole }(\mathrm{mm}) \\
n_{h} & =\text { number of holes. }
\end{aligned}
$$

\section{EXPERIMENTAL VERIFICATION}

Experimental verification for T-type and B-type corner connection designed according to the previous suggestion in Sec. 2 was conducted under moment reversal.

(1) Detail of specimens

For T-type connection as shown in Fig. 11 a) the main reinforcing bars having $8 d_{b}$ of bend radius and $360 \mathrm{~mm}$ tail extension length were provided for negative moment. Three steel web plates of $3.2 \mathrm{~mm}$ thickness and three deformed bars of $10 \mathrm{~mm}$ diameter were placed for positive moment. U-shaped bars were also provided for confining concrete against edge effect. In B-type connection, detailing for only positive moment were considered by providing hook bar and inner plate of $3.2 \mathrm{~mm}$ thickness as shown in Fig. $11 \mathrm{~b}$ ) .

\section{( 2 ) Test results}

Satisfactory results of ultimate strength were found for both specimens subjected to moment reversal as given in Table 2 except B-type specimen under negative moment. The premature failure of welding joint between outer flange of sandwich wall and that of open-sandwich slab was found in B-type specimen during

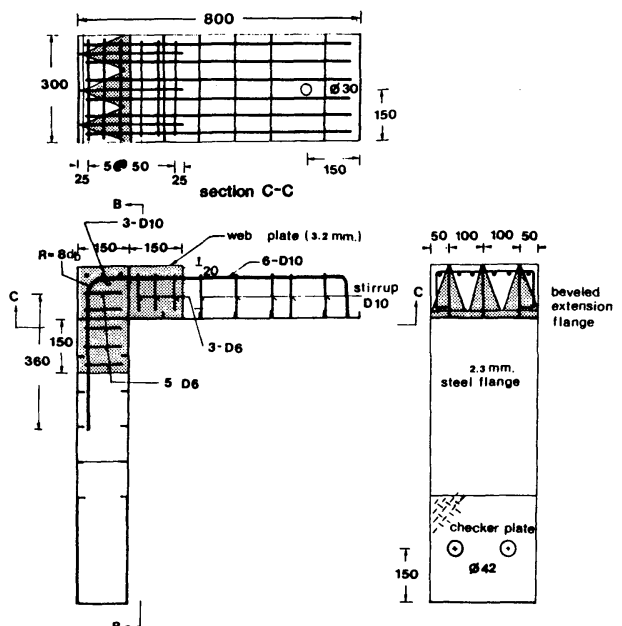

a) $\mathrm{T}$-type section B-B

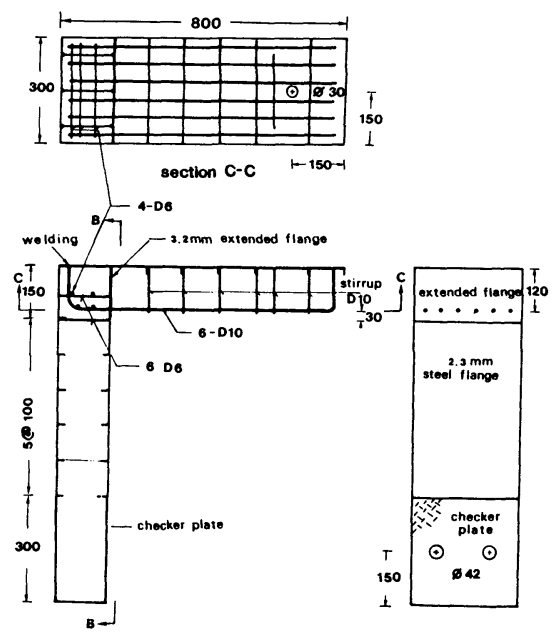

b) B-type section B-B

Fig. 11 Detail arrangement in corner of test specimen. 
Table 2 Comparison of Ultimate Strength between Test Results and Calculated Values.

\begin{tabular}{c|c|c|c}
\hline & $\begin{array}{l}\text { TEST } \\
\text { RESULTS } \\
\text { SPECIMEN }\end{array}$ & $\begin{array}{c}\text { CALCULATED } \\
\text { SANDWICH } \\
(\mathrm{kN})\end{array}$ & $\begin{array}{c}\text { FLEXURE STRENGTH } \\
\text { OPEN-SANDWICH } \\
(\mathrm{kN})\end{array}$ \\
\hline T-TYPE CORNER & & & \\
NEGATIVE MOMENT & 51.5 & $52.0 *$ & 42.2 \\
POSITIVE MOMENT & 51.5 & 49.8 & 59.8 \\
B-TYPE CORNER & 46.1 & $52.8 *$ & 59.8 \\
NEGATIVE MOMEN'T & 44.1 & $44.7 *$ & 42.2 \\
\hline
\end{tabular}

NOTE : Neglecting contribution of web and concrete tension $\mathrm{fo}_{\mathrm{o}}=40.7 \mathrm{MPa}$

: $\mathrm{f}_{y \mathrm{r}}=382 \mathrm{MPa}, \mathrm{f}_{y \mathrm{r}}=314 \mathrm{MPa}, \mathrm{f}_{y w}=304 \mathrm{MPa}$

- Neglecting compression steel flange

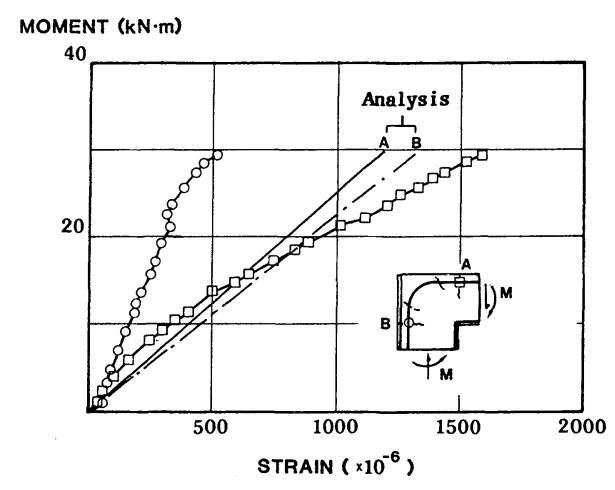

Fig. 13 Comparison between test results and analysis of reinforcement strain at the face of corner joint.
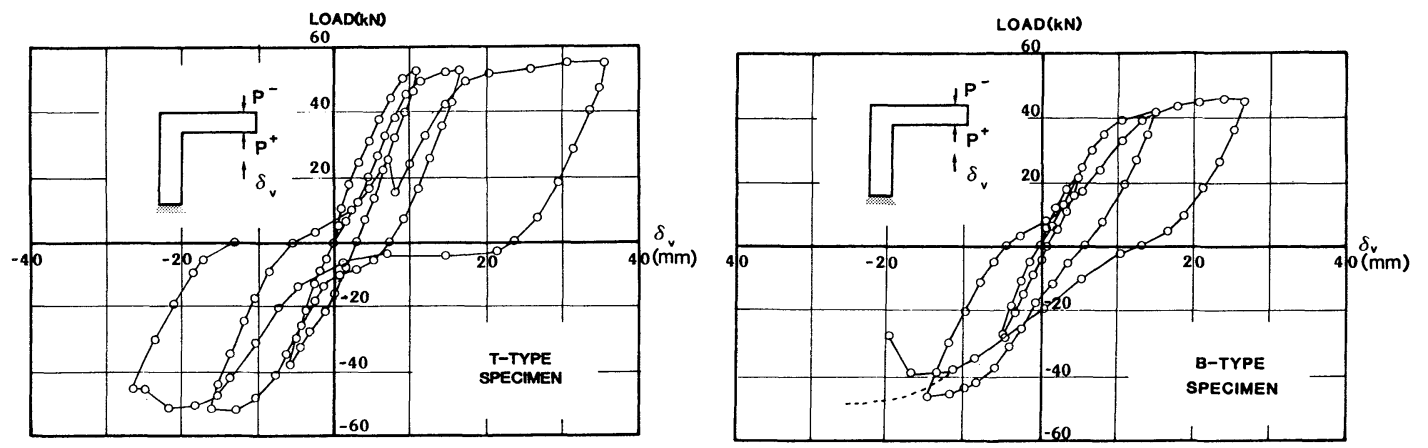

Fig. 12 Load-deflection curve.

application of negative moment, while flexure failure of sandwich wall was observed in T-type specimen. Evidence from the previous results revealed that B-type connection subjected to negative moment can satisfy strength requirement for corner connection when strong enough welding jont of outer flange is provided. Therefore, it can be concluded that corner connection between sandwich and open-sandwich member designed according to previous suggestion can meet strength requirement even under moment reversal. Ductile behavior also can be observed in load-deflection curve $P-\delta_{v}$ for both specimens as shown in Fig. 12.

From the observed bar strain at the faces of corner shown in Fig. 13, it is shown that the bar strain at the sandwich wall side is approximately one third of predicted value, while the strain at the open-sandwich slab side is nearly the same the predicted value. This is because of composite action created in the joint core. Besides this web could also provide a good confinement for tail extension. In the consequence, the required tail extension length or area of reinforcing bars can be somehow reduced when corner connection is designed against moment reversal. According to this corner connection, tail extension length may be factored by 0.5 .

\section{PROPOSED DESIGN METHOD}

Based on these available data, the design method for corner connection between sandwich and open-sandwich composite members subjected to bending moment is proposed under the conditions that

1) properly designed rib shear connector is provided,

2) shear force is not a dominant design load for the corner connection,

3) proper design of welding joint is presumed. 


\section{(1) T-type corner connection}

T-type corner connection against negative moment shall be designed as follows

1) The outer flange of sandwich member should be prolonged up to top surface of open-sandwich member.

2) The main reinforcing bar of open-sandwich member shall be bent in the corner with the tail extension embedded in the sandwich member. The bend radius of main reinforcement shall be computed from Eq. (1) but shall not be greater than $0.8 \mathrm{~h}$.

The tail extension length $\left(l_{t}\right)$, which is defined as the length of straight part between the end of bend and the end of bar, shall satisfy Eq. (7).

$l_{t} \geqq l_{s}$

where $l_{s}=$ lapped length between outer flange of sandwich member and reinforcing bar which is defined as the length between first effective rib on the outer flange to the end of reinforcing bar.

The effective rib shall not be located in the corner core. The required lapped length shall be calculated based on Eq. (2). The ratio between side covering and bottom covering shall not be larger than two because other than side splitting failure may be expected.

3) Additional anchorage reinforcement shall be provide for preventing delamination of outer flange of sandwich member as shown in Fig. 14 a).

Under positive moment, design of T-type corner connection shall be based on the following.

1) Web steel plate shall be provided according to Eq. (3) and arranged uniformly in the corner with a spacing that meets requirement for adequate placing of concrete. Web steel also shall be extended from both faces of corner at least equal to the depth of member.

2) Each inner flange shall be beveled and extended along the face of corner in order to make the possibility of transferring forces from steel flange to web panel, arrangement of reinforcement and casting of concrete in the corner core as shown in Fig. $14 \mathrm{~b}$ ).

3) Transverse reinforcement shall be provided as shear key according to Eq. (4). The required transverse reinforcement shall be placed within compression zone with spacing not less than five times of its diameter.

The above design requirements shall be combined for corner connection subjected moment reversal. However additional anchorage bar can be omitted and lapped length can be reduced to half of the required length computed from Eq. (2).

\section{( 2 ) B-type corner connection}

For B-type corner connection subjected to negative moment, it shall be confirmed that the outer flanges of both adjoining members are welded at the corner so as to develop yield force in the both flanges. For B-type corner connection subjected to positive moment, the design shall be done as follows

1) Bent up standard hook bars as shown in Fig. 15 shall be arranged in the corner. The required

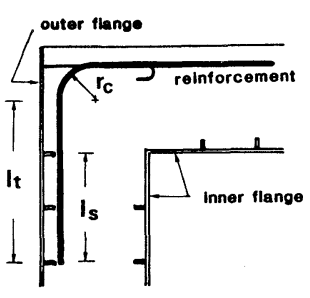

a) Negative moment

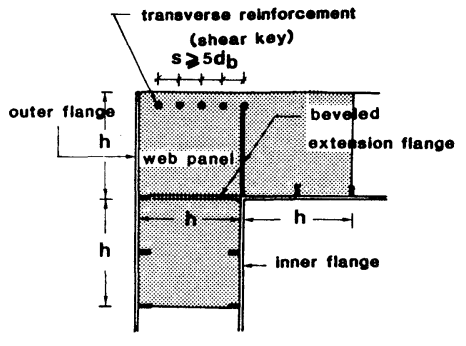

b) Positive moment

Fig. 14 Proposed detail arrangement of T-type corner connection.

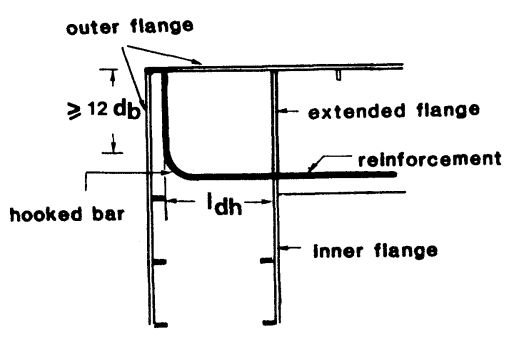

Fig. 15 Proposed detail arrangement of B-type corner connection against moment reversal. 
development length $\left(l_{a h}\right)$ shall be determined by Eq. (5),

2) The inner flange shall be extended and its thickness shall be given according to Eq. (6).

Against moment reversal, the corner connection shall be designed so as to satisfy design requirements for negative moment and positive moment together. And joint core shall be provided by some confinement.

\section{CONCLUDING REMARKS}

Experiments of corner connections between sandwich and open-sandwich members with various joint detailings have been conducted as a case study of corner connection between different types of structural member. Based on the test results, the design method for the corner connection was proposed.

The design method can cover the design for not only corner but also straight connections of the members which can be composite members having one facing or both facings as steel plate.

The proposed method includes the basic design method for connection between different types of structural member which are tensile force transfer at the corner between bars (Eq. (1)), tensile force transfer between reinforcing bar and steel plate (Eq. (2)) and compression force transfer between concrete and steel plate through shear key (Eq. (4)).

\section{ACKNOWLEDGMENTS}

Sincere thank is expressed to Prof. Hajime OKAMURA of the University of Tokyo for his valuable guidance and Nippon Kokan Co. Ltd. for providing financial aid on the experimental works throughout this study. This paper was the summarizes of Doctoral dissertation submitted to University of Tokyo.

\section{REFERENCES}

1) ACI Committee 318: Building Code Requirements for Reinforced Concrete (ACI 318-83), American Concrete Institute, Detroit, pp. 1-111, 1983.

2) JSCE Concrete Committee on Limit State Design : Recommendations for Limit State Design of Concrete Structures, Concrete Library of JSCE, No. 4, pp. 1-102, Dec. 1984.

3) Rungrojsaratis, V. : Corner Connection Joints between Sandwich and Open-sandwich of Steel-Reinforced Concrete Composite Structure, Doctoral Dissertation Submitted to Dept. of Civil Eng., Univ. of Tokyo, March 1987.

4) Rungrojsaratis, V., Ueda, T. and Ozawa, K. : The Capacity of Lapped Splice between Steel Bars and Steel Plate, Proc. of JCI Annual Conference, Vol. 10, 1988 (will be published).

5) Narui, S., Kousaka, Y. and Toyosawa, Y. : Leonhardt Concrete Course III : Detailing of Reinforced Concrete, Kajima Press, pp. 188-204, May 1985.

6) Joint Committee of WRC and ASCE : Plastic Design in Steel : A Guide and Commentary, ASCE Manuals and Reports on Engineering Practice, No. 41, second edition, New York, pp. 167-186, 1971.

7) Ikeda, S., Ohmachi, T., Mori, A. and Yamaguchi, T. : Shear Transfer between Steel and Concrete by Stud Connectors, Trans. of JCI, Vol. 3, pp. 461-468, 1981.

8) Nilsson, I. H.E. and Losberg, A. : Reinforced Concrete Corners and Joints Subjected to Bending Moment, Proc. of ASCE, ST 6, Vol. 102, pp. 1229-1253, June, 1976.

9) ACI-ASCE Committee 352 : Recommendation for Design of Beam-Column Joints in Monolithic Reinforced Concrete Structure, ACI Journal, Vol. 82, No. 3, pp. 266-283, May-June, 1985 